New Zealand journal of industrial relations, 1986, 11, 105-117

\title{
Occupational and industrial change in the New Zealand workforce
}

\section{David F Smith*}

This paper examines changes in the occupational and industrial composition of the New Zealand workforce between 1956 and 1981 with particular emphasis upon white-collar employment. The research study from which the data are derived examined the growth and unionisation of New Zealand's white-collar workforce, and was completed in 1984 (Smith, 1984). Though the main aim of the research was to examine white-collar unionism, it produced valuable data on occupational and industrial change which it is felt would be of interest to a wider audience. Data are presented on changes to the occupational and industrial composition of the workforce, including inter-industry employment changes, the growth of white-collar occupations, and the gender composition of the white-collar workforce. The paper concludes with an examination of the relative impact of industry and occupation effects upon changes in the workforce structure.

\section{Introduction}

The purpose of this paper is to examine changes in the occupational and industrial composition of the New Zealand workforce between 1956 and 1981 with particular emphasis upon white-collar employment. The data presented here are derived from a research project on white-collar unionism (Smith, 1984), which produced valuable information on occupational and industrial change, and which it is believed is likely to be of sufficient interest in itself to be made available to a wider audience.

There are several reasons for taking an interest in changes in workforce structure. Behind the changing employment structure of a country lie changes in the social organisation of production and the division of labour. These in turn may be closely linked with the study of social stratification and class. Considerable debate surrounds the reasons for such changes. There are some who argue that they arise from the industrialisation process itself (Kerr, Dunlop. Harbison and Myers, 1973); whilst others (Braverman, 1974) believe that the organisation of work and the process of industrialisation under capitalism are the keys to understanding occupational and industrial change.

Apart from this theoretical concern, there are practical concerns. Changes to the industrial structure of a country result in the contraction of some areas of employment and the expansion of others. Changes to the occupational distribution of employment are brought about by the changing demand for skills, different production techniques, and changing work methods. There are thus manpower planning implications for government in the areas of industrial and occupational change. Monitoring shifts in employment is a vital step in any attempt to plan and adjust employment policies to changing circumstances.

Changes in the occupational structure of a country may be thought of as arising out of 2 proximate causes: changes to the industrial structure of the country, and changes to the occupational distribution of labour within industries. Changes in the pattern of demand for goods and services lead to the expansion of certain sectors of the economy and a contraction

The research reported here was carried out with financial assistance from the following sources whose help is gratefully acknowledged: Social Sciences Research Fund, University Grants Committee, BP Industrial Research Award, Victoria University of Wellington Internal Research Committee.

Valuable comments were received from the symposium editor and the referees. 
of others. By the same token, new methods of production, brought about as a result of changed working practices or the introduction of new technology, may alter the demand for labour or the level and type of skill required within an industry, even though the position of the industry itself within the economy as a whole remains relatively stable. Thus, although these changes may occur independently; the reallocation of labour within industries and the redistribution of labour between industries, it is most likely that in most economies, both occur simultaneously.

New methods of work and work organisation, changes in technology and changes in the composition of the workforce all involve the making redundant of old skills and the emergence of new ones. Jobs disappear whilst new ones are created to take their place. In analysing employment change, it is desirable to examine its occupational as well as its industrial character. Changes to the occupational structure of employment can occur independently of its industrial distribution, and an industry-based classification of employment alone does not reveal the occupational composition of each industry sector. This paper will examine the changes which have taken place in the structure of the New Zealand workforce, in particular, the growth of the white-collar component, and relate these to changes in the industrial structure and to changes in the occupational distribution of labour within industries.

\section{Methodological issues}

An examination of occupational change poses some very severe difficulties. In the first place, there is the difficulty of classifying the workforce into general groupings, for example by dividing it into white-collar and manual, even assuming that this distinction is a useful one. The categorisation of the workforce in this way is by no means straightforward. Whatever might be the merits of leaving the precise boundaries of these 2 groups rather vague from the point of view, for example, of the theoretical debate over the class position of the white-collar worker, this approach is just not satisfactory for the researcher who must identify groups and individuals whose numbers can be counted. This involves giving a precise and limited meaning to terms which are often used in a discursive fashion in the theoretical literature. Such clinical precision is necessary if concepts are to be operationalised and measured using available data sources.

A second difficulty concerns the preparation of estimates of changes to the structure of the New Zealand workforce, and the size of the white-collar component. Unfortunately, there existed until recently, no comprehensive or reliable data on the proportions of white-collar and manual workers in the labour force. The quinquennial census of population is the only detailed and comprehensive estimate of the industrial distribution of employees by occupation. However, the disruptions to continuity caused by frequent changes to the system of occupational classification used in New Zealand since census data were first gathered, means that it is impossible to carry out a meaningful analysis of labour force trends without considerable reclassification work. Such a reclassification of labour force statistics was carried out by the author in a preliminary way in 1981 (Smith, 1981). The results of this reclassification are used here in an expanded and updated form in order to make meaningful comparisons over time. This paper uses census data on occupations for the census years 19561981. The issue of occupational classification itself presents a number of problems, and several competing schemes are discussed in the literature. Dissatisfaction with the shortcomings of prestige-based scales for measuring socio-economic status led Elley and Irving (Elley and Irving, 1976; Irving and Elley, 1977) to develop a descriptive scale for New Zealand which has been widely used for research purposes. However, this scale is considered unsuitable for this present research, which focuses upon occupational classification rather than socio-economic status, though clearly occupation may be an important component of status. For convenience, and to expedite comparison with research already carried out overseas, particularly in the United Kingdom, the scheme devised by Routh (1980, pp 3-5, and Appendix A) with modifications incorporated by Bain (1970. pp 189-190) is used here, though with some further minor modifications to take account of New Zealand conditions.

The term "occupation" refers to the job the worker does. Occupations are grouped together under the title of an occupational category, which describes what can roughly be distinguished as a group of jobs, closely enough related to be performed by people of the same sort of skill, using similar materials and techniques in the same sort of environment. These are referred to as "occupational categories" to distinguish them from social classes or socio- 
economic groups developed for other purposes. This scheme for occupational categorisation is set out below:

1. Employers and self-employed

2. All white-collar workers

a. higher professionals

b. lower professionals

c. administrators and managers

d. clerical workers

e. salesworkers

f. foremen, inspectors and supervisors

3. All manual workers

For the 1971 New Zealand census, the classification scheme for census data was changed from that which had been used for the earlier censuses of 1966, 1961 and 1956. This change, which was major, had a considerable effect upon the comparability of the 1971 census figures for both industries and occupations with those of earlier years. Further minor changes were made to the classification system used in 1976. Meaningful comparison of occupational data from different census years is made possible only by reclassifying the data. For this reason, census data on occupations for 1956, 1961, 1966, 1976 and 1981 have been recast in accordance with the 1971 classification ${ }^{2}$.

It was necessary to use a lesser time period than 1956-1981 for the examination of changes to the industrial composition of the workforce. Apart from the major changes to the method of classifying occupations discussed above, major changes also took place in the method of classifying industries. Since the reclassification of industries was too major a task to be carried out, data from the period 1971-1981 are used. Although this gives a shorter time period for the study of changes in industries, and in occupations according to industry, it is nevertheless all that is possible with currently available data.

The analysis below will focus upon changes in the occupational composition of the New Zealand labour force from 1956-1981; the gender composition is also examined for the same period. Finally, changes in the industrial composition of the workforce are discussed, including inter-industry employment changes and the growth of white-collar occupations by industry. By the inclusion of 1981 census data, these sections update material published previously by the author (Smith, 1981). The paper concludes with an examination of the industry and occupation effects on changes in the New Zealand workforce structure.

\section{Occupational composition}

One of the most prominent features of the period 1956-1981 is the distinct shift towards employment in white-collar occupations. The growth in the number of white-collar workers in New Zealand has paralleled that taking place in other countries (Price and Bain, 1983). During this period, employment in white-collar occupations rose by 272572 , or 105 percent, and its share of total employment rose from 32.6 percent to 42.7 percent. By contrast, employment in manual occupations rose by 158220 , or 41 percent, and its share of employment fell from 48.2 percent to 43.5 percent over the same period.

Figure 1 illustrates the changing structure of the workforce in diagramatic form.

The changes outlined in Figure 1 are illustrated in greater detail in Table 1, which shows the growth indices which have been calculated for each occupational category, and the changes that have taken place between 1956 and 1981.

Although the proportion of total employment accounted for by white-collar employees rose over the period under discussion, there are marked differences in growth between the groups which make up the ranks of the white-collar workers. Table 1 shows that managers and administrators; lower professionals; foremen, inspectors and supervisors; and higher professionals are the groups which have grown at the greatest rate, all of these groups more than doubling in numbers over the period. Clerical workers continue to be the largest whitecollar group in the workforce, increasing its share of the total workforce to 14.1 percent from obtained from the author upon request. 
Figure 1: The changing occupational structure of New Zealand

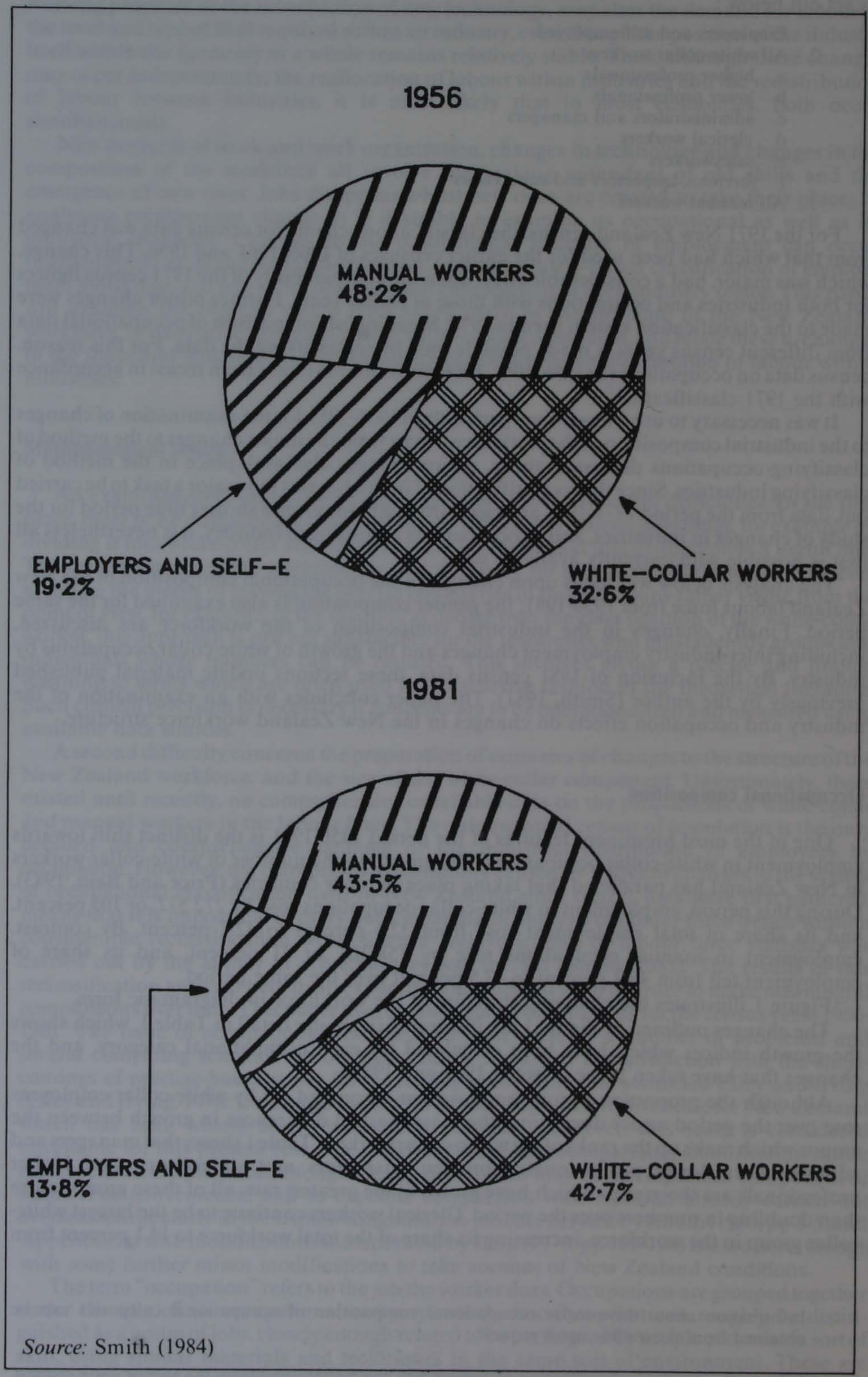




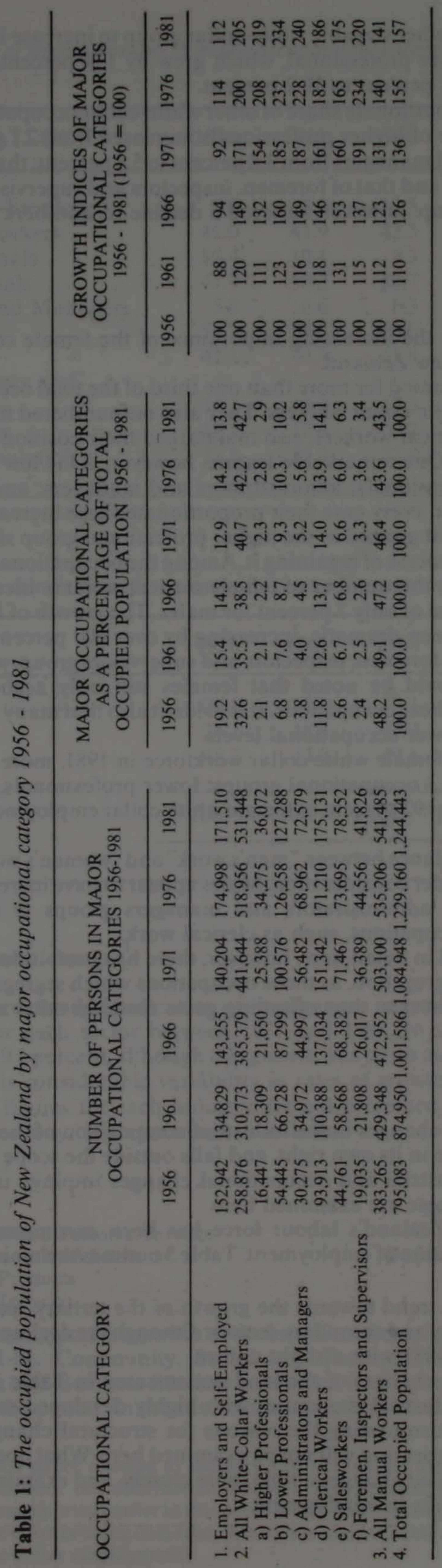


11.8 percent in 1956. The other sizeable white-collar group to increase its proportionate share of the workforce was lower professional, which grew by 134 percent, with its share of the workforce rising from 6.8 percent to 10.2 percent.

The growth in the proportionate share of other white-collar occupational groups has been more moderate: the share of higher professionals increased from 2.1 percent to 2.9 percent; that of administrators and managers from 3.8 percent to 5.8 percent; that of salesworkers from 5.6 percent to 6.3 percent; and that of foremen, inspectors and supervisors from 2.4 percent to 3.4 percent. This last group, however, suffered a decline in numbers in 1981.

\section{Gender composition}

Table 2 demonstrates the increasing importance of the female component of the total occupied workforce of New Zealand.

By 1981, females accounted for more than one third of the total occupied population and almost one half of the white-collar workers. They also outnumbered males among the lower professionals and the clerical workers, and maintained their position at just under half the number of salesworkers. One remarkable feature, however, is the low proportion of women amongst the higher professionals; administrators and managers; and foremen, inspectors and supervisors, though in every case their proportionate share increased in 1981. However, females appear to have lost ground in the higher professional group since 1956, though they now appear to be in the process of regaining it. Among the occupational groups where female growth has been greatest, the number of female clerical workers increased by 148 percent compared with an increase of only 7 percent for males. The growth of female administrators and managers has also been dramatic, increasing by over 400 percent; so too has been the increase in females in the foremen, inspectors and supervisors group, with an increase of 261 percent. However, it should be noted that females still only account for a very small proportion of workers in these occupations. It is evident also that many females who enter the workforce do so at the lower occupational levels.

Of the total occupied female white-collar workforce in 1981, more than 50 percent were clerical workers, and the 3 occupational groups: lower professionals, clerical workers and salesworkers accounted for 92 percent of female white-collar employment, only 2 percent less than 25 years earlier.

It is clear that the imbalance between "men's work" and "women's work" has changed little during the time period under consideration. Males appear to have increased their share of the higher professional and administrators and managers groups at the expense of their participation in other occupations, such as clerical work.

Though not examined in detail here, however, there has been little change in the overall degree of occupational segregation, as those occupations which segregate the most have also been growing at the fastest rate, thus offsetting gains made in other areas (Smith, 1983).

\section{Industrial composition}

A detailed analysis of changes in the industrial composition of the workforce in general would be a major exercise in its own right, and falls outside the scope of this present paper. However, insofar as industrial and occupational changes impinge upon the study of the white-collar workforce, these are examined here.

The growth of New Zealand's labour force has been accompanied by inter-sectoral movements in the distribution of employment. Table 3 outlines the main changes which have taken place since 1936 .

Table 3 illustrates the trend towards the growth of the tertiary sector with a decline in employment in the primary and secondary sectors; although the decline of the former appears to have been arrested in 1981 with a slight upturn.

It is often argued that changes of the kind documented in Table 3 are typical of those observed in advanced industrial economies with highly developed secondary and tertiary sectors. The arguments surrounding the reasons for structural changes of this type were alluded to earlier in the paper and will not be examined here. What does remain, however, is the need to study the detailed changes a little more closely, and examine the implications of these for occupational shifts in employment. 
Table 2: The percentage of female workers in major occupational categories in New Zealand 1956 1981

\begin{tabular}{lrrrrrr}
\hline OCCUPATIONAL CATEGORY & 1956 & 1961 & 1966 & 1971 & 1976 & 1981 \\
\hline 1. Employers and Self-Employed & 9.0 & 8.0 & 10.5 & 13.0 & 15.6 & 18.3 \\
2. All White-Collar Workers & 41.0 & 41.9 & 42.5 & 44.0 & 46.5 & 48.9 \\
a) Higher Professionals & 15.4 & 10.4 & 9.3 & 8.0 & 9.4 & 13.3 \\
b) Lower Professionals & 47.9 & 50.2 & 49.7 & 53.1 & 53.6 & 56.2 \\
c) Administrators and Managers & 5.8 & 6.6 & 6.3 & 7.5 & 10.2 & 12.3 \\
d) Clerical Workers & 56.3 & 57.9 & 60.0 & 66.5 & 71.8 & 75.0 \\
e) Salesworkers & 47.1 & 44.7 & 43.8 & 42.7 & 47.1 & 46.4 \\
f) Foremen, Inspectors and & 10.1 & 10.9 & 12.3 & 9.5 & 12.9 & 16.6 \\
$\quad$ Supervisors & 18.1 & 18.6 & 20.2 & 22.2 & 22.4 & 23.7 \\
3. All Manual Workers & 23.8 & 25.2 & 27.4 & 29.9 & 31.6 & 33.7 \\
4. Total Occupied Population & & & & & & \\
\hline
\end{tabular}

Table 3: The percentage distribution of employees by economic sector in New Zealand 1936 - 1981

\begin{tabular}{lcccccc}
\hline SECTOR & 1936 & 1961 & 1966 & 1971 & 1976 & 1981 \\
\hline Primary & 27.1 & 15.2 & 13.7 & 12.0 & 10.5 & 11.2 \\
Secondary & 24.2 & 35.8 & 37.2 & 34.7 & 34.1 & 30.9 \\
Tertiary (Service) & 48.7 & 49.0 & 49.1 & 53.3 & 55.4 & 57.9 \\
TOTAL & 100 & 100 & 100 & 100 & 100 & 100 \\
\cline { 2 - 7 }
\end{tabular}

\section{Inter-industry employment changes ${ }^{3}$}

Table 4 gives a more detailed indication of the changes in total employment and whitecollar employment for each sector between 1971 and 1981. In this 10 year period, total employment grew by 19.1 percent, although this growth was by no means spread evenly across all sectors, and there is considerable variability in rates of growth for different industries.

Although detailed figures for each industry are not presented in the table, in order of magnitude, the changes may be summarised as follows:
Growing industries
Basic Metals
Community, Social and Personal Services
Financing, Insurance, Real Estate etc.
Paper and Paper Products
Food, Beverages, Tobacco

\author{
Declining industries \\ Mining and Quarrying
Textiles
ding and Construction
}

This summary is based upon the growth or decline of total employment in these industries over the period 1971-81. Community, Social and Personal Services; and Financing, Insurance, Real Estate and Business Services accounted for 83 percent of the growth in the tertiary sector, during the period. In the case of the secondary sector, such modest growth as

3 Figures cited in this paper relating to industry and occupation are derived from unpublished census data which does not differentiate between occupational statuses. The figures differ, therefore, from those reported earlier in this paper which do so distinguish and which are therefore more accurate. The effect of using data from this source is to overstate slightly the proportion of the workforce in white-collar employment. 
Table 4: Distribution of total employment and white-collar employment by sector 1971 and 1981

\begin{tabular}{|c|c|c|c|c|c|c|c|}
\hline \multirow{2}{*}{ SECTOR } & \multicolumn{3}{|c|}{ TOTAL EMPLOYMENT } & \multicolumn{3}{|c|}{ WHITE-COLLAR EMPLOYMENT } & \multirow{2}{*}{$\begin{array}{l}\% \text { Growth } \\
\text { in Employ- } \\
\text { ment Account- } \\
\text { ed for by } \\
\text { White-Collar } \\
\text { Workers }\end{array}$} \\
\hline & 1971 & 1981 & $\begin{array}{c}\% \\
\text { change }\end{array}$ & 1971 & 1981 & $\begin{array}{c}\% \\
\text { change }\end{array}$ & \\
\hline Primary & 134.159 & 148,911 & +11.0 & 9,844 & 9.505 & -3.4 & - \\
\hline Secondary & 388,071 & 411,990 & +6.2 & 94,417 & 106,821 & +13.1 & 51.9 \\
\hline Tertiary & 582,797 & 725,475 & +24.5 & 372,357 & 466,586 & +25.3 & 66.0 \\
\hline All Sectors & $1,105,027$ & $1,286,376$ & +16.4 & 476,618 & 582,912 & +22.3 & 58.6 \\
\hline
\end{tabular}

Not

Adequately

\begin{tabular}{lll} 
Defined & 13,808 & 45,960 \\
\hline
\end{tabular}

Total in

Employment $\quad 1,118,835 \quad 1,332,336^{*} \quad+19.1$

* Random rounding introduced for the first time in 1981 may mean that these figures may not exactly match published census totals.

did occur was provided by Manufacturing, with Food, Beverages and Tobacco and Fabricated Metals accounting for around two thirds of this. The decline in Mining and Quarrying offset some of the growth in Agriculture, Hunting, Forestry and Fishing with which it is grouped in the primary sector, thus reducing the overall rate of growth of this sector.

It is clear, however, that overall, it was the growth of the tertiary sector which was responsible for the bulk of the growth in employment in the years 1971-81. Excluding those workers not adequately defined by industry, almost four fifths of the growth in total employment was accounted for by the growth in the tertiary sector.

Turning to the growth in white-collar employment, once again growth rates for different' industries differed considerably. In general terms, however, those industries which show the greatest growth in total employment also show the greatest growth in white-collar employment. Across all industries, 58.6 percent of the growth in total employment was accounted for by the growth in the number of white-collar workers. As may be seen from Table 4, the part played by the tertiary sector in overall employment growth was substantial. It is hardly surprising therefore that about 89 percent of the growth in total white-collar employment was accounted for by the tertiary sector.

\section{White-collar occupations and industries}

The distribution of white-collar occupations is obviosly related to the nature of the work carried out in a particular industry. Wholesale and Retail Trade and Restaurants and Hotels, for example, has a high proportion of white-collar workers as a result of the numbers of salesworkers in this industry. By the same token, the high percentage of white-collar workers in Financing, Insurance, Real Estate and Business Services is explained by the presence of large numbers of clerical workers; and in Community, Social and Personal Services, by the large number of lower professionals. The distribution of employment in white-collar occupations according to industry is more clearly seen in Table 5 , which shows employment in various white-collar occupations as a percentage of total white-collar employment and total employment in each industry for the census years 1971-81. 
Occupational and industrial change

113

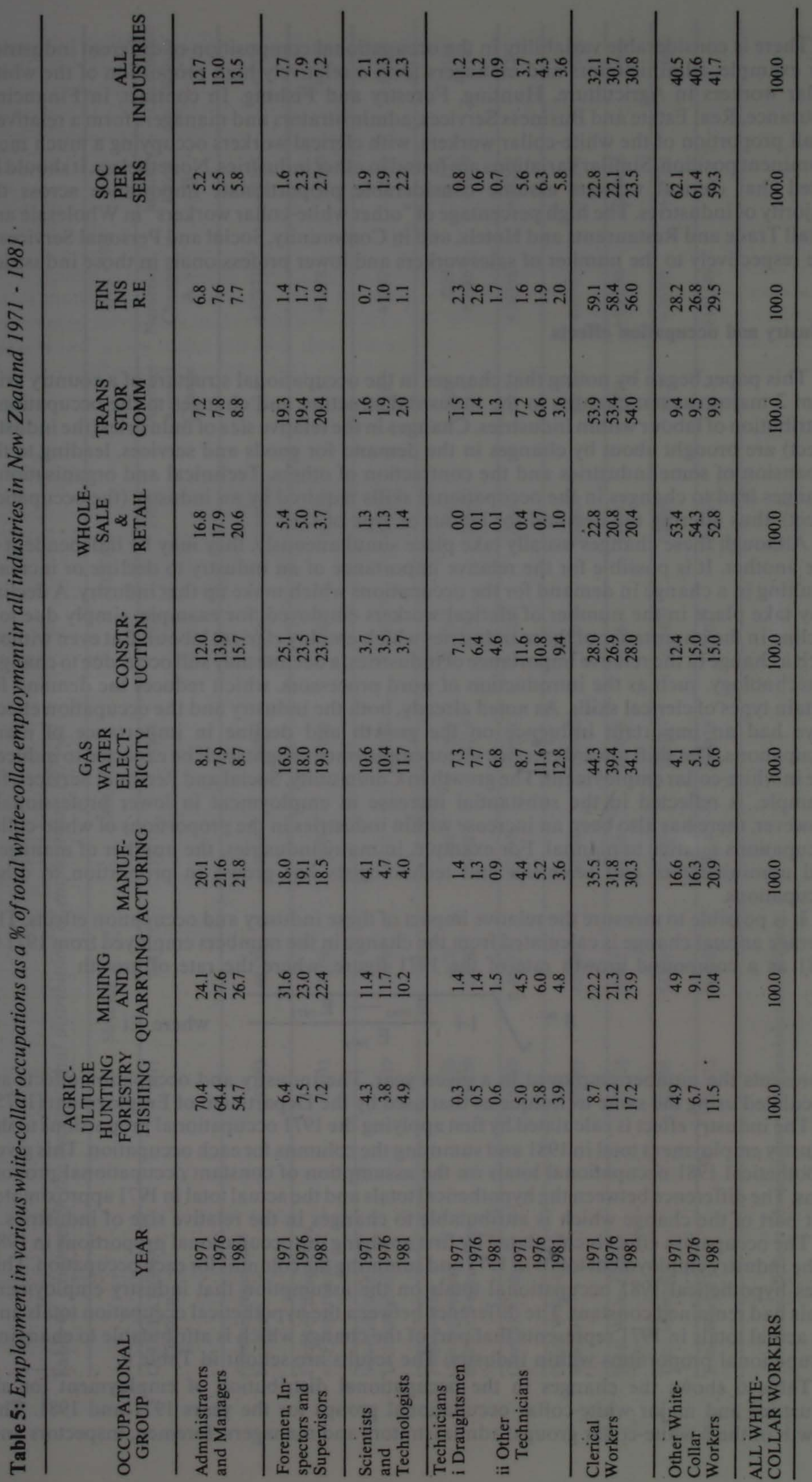




\section{David F Smith}

There is considerable variability in the occupational composition of different industries. For example, administrators and managers form a relatively high proportion of the whitecollar workers in Agriculture, Hunting, Forestry and Fishing. In contrast, in Financing. Insurance, Real Estate and Business Services, administrators and managers form a relatively small proportion of the white-collar workers, with clerical workers occupying a much more prominent position. Similar variations are found in other industries. Nonetheless, it should be noted that clerical workers assume considerable proportionate importance across the majority of industries. The high percentage of "other white-collar workers" in Wholesale and Retail Trade and Restaurants and Hotels, and in Community, Social and Personal Services is due respectively to the number of salesworkers and lower professionals in those industries.

\section{Industry and occupation effects}

This paper began by noting that changes in the occupational structure of a country arise from 2 major causes; changes to the industrial structure and changes to the occupational distribution of labour within industries. Changes in the relative size of industries (the industry effect) are brought about by changes in the demand for goods and services, leading to the expansion of some industries and the contraction of others. Technical and organisational changes lead to changes in the occupational skills required by an industry (the occupation effect), thus altering the demand for labour or type of skill.

Although these changes usually take place simultaneously, they may be independent of one another. It is possible for the relative importance of an industry to decline or increase resulting in a change in demand for the occupations which make up that industry. A decline may take place in the number of clerical workers employed, for example, simply due to a decline in the importance of those industries which employ clerical labour. But even without such a change in the relative importance of industries, a decline may still occur due to changes in technology, such as the introduction of word processors, which reduces the demand for certain types of clerical skills. As noted already, both the industry and the occupation effects have had an important influence on the growth and decline in importance of many occupations. The shift towards service sector employment might itself be expected to induce a rise in white-collar employment. The growth in Community, Social and Personal Services, for example, is reflected in the substantial increase in employment in lower professionals. However, there has also been an increase within industries in the proportions of white-collar occupations relative to manual. For example, in many industries, the number of managers and administrators and scientists and technologists has grown in proportion to other occupations.

It is possible to measure the relative impact of these industry and occupation effects. The average annual change is calculated from the change in the numbers employed from 1971 to 1981 as a compound growth rate of the 1971 figure, where the rate of growth

$$
g=\sqrt[10]{1+\frac{E_{1981}-E_{1971}}{E_{1971}}} \text { where Et }
$$

represents the number employed in a given year. The industry and occupation effects are calculated using the same technique as that used by the Department of Employment (1975).

The industry effect is calculated by first applying the 1971 occupational proportions to the industry employment total in 1981 and summing the columns for each occupation. This gives hypothetical 1981 occupational totals on the assumption of constant occupational proportions. The difference between the hypothetical totals and the actual total in 1971 approximates that part of the change which is attributable to changes in the relative size of industries.

The occupation effect is calculated by first applying the occupational proportions in 1981 to the industry employment totals in 1971 and summing the columns for each occupation. This gives hypothetical 1981 occupational totals on the assumption that industry employment totals had remained constant. The difference between the hypothetical occupation totals and the actual totals in 1971 represents that part of the change which is attributable to changing occupational proportions within industry. The results are set out in Table 6.

Table 6 shows the changes in the occupational distribution of employment for all industries and major white-collar occupational groups for the years 1971 and 1981. The growth of the 3 white-collar groups: administrators and managers; foremen, inspectors and 
Occupational and industrial change 115

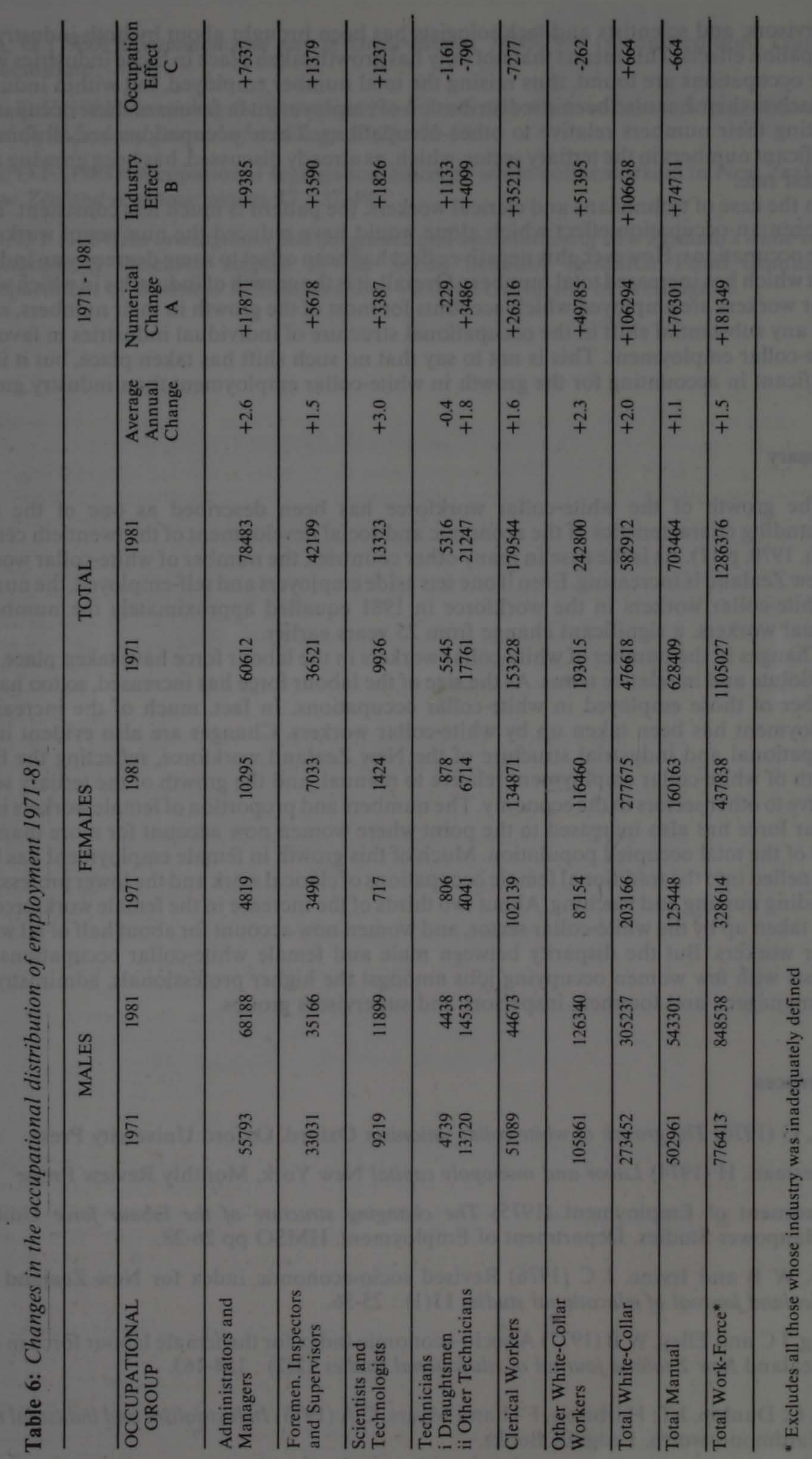


supervisors; and scientists and technologists has been brought about by both industry and occupation effects. This means that not only has growth taken place in those industries where these occupations are found, thus raising the total number employed, but within industries themselves there has also been a redistribution of employment in favour of these occupations, boosting their numbers relative to other occupations. These occupations are all found in significant numbers in the tertiary sector, which, as already discussed, has been growing at the greatest rate.

In the case of technicians and clerical workers, the pattern is much less consistent. There has been an occupation effect which alone would have reduced the number of workers in those occupations. However, this negative effect has been offset to some degree by an industry effect which has increased total numbers. Overall, it is the growth of industries in which whitecollar workers are employed which accounts for most of the growth in their numbers, rather than any substantial shift in the occupational structure of individual industries in favour of white-collar employment. This is not to say that no such shift has taken place, but it is less significant in accounting for the growth in white-collar employment than industry growth.

\section{Summary}

The growth of the white-collar workforce has been described as one of the most outstanding characteristics of the economic and social development of the twentieth century (Bain, 1970, p 11). As is the case in many other countries, the number of white-collar workers in New Zealand is increasing. Even if one sets aside employers and self-employed, the number of white-collar workers in the workforce in 1981 equalled approximately the number of manual workers, a significant change from 25 years earlier.

Changes in the number of white-collar workers in the labour force have taken place both in absolute and in relative terms. As the size of the labour force has increased, so too has the number of those employed in white-collar occupations. In fact, much of the increase in employment has been taken up by white-collar workers. Changes are also evident in the occupational and industrial structure of the New Zealand workforce, reflecting the faster growth of white-collar employment relative to manual, and the growth of the tertiary sector relative to other sectors in the economy. The numbers and proportion of female workers in the labour force has also increased to the point where women now account for more than one third of the total occupied population. Much of this growth in female employment has been channelled into the traditional female occupations of clerical work and the lower professions, including nursing and teaching. About two thirds of the increase in the female workforce has been taken up by the white-collar sector, and women now account for about half of all whitecollar workers. But the disparity between male and female white-collar occupations still persists with few women occupying jobs amongst the higher professionals, administrators and managers, and foremen, inspectors and supervisors groups.

\section{References}

Bain, G (1970) The growth of white-collar unionism Oxford, Oxford University Press.

Braverman, H (1974) Labor and monopoly capital New York, Monthly Review Press.

Department of Employment (1975) The changing structure of the labour force Unit for Manpower Studies, Department of Employment, HMSO pp 26-28.

Elley, W B and Irvine, J C (1976) Revised socio-economic index for New Zealand New Zealand journal of educational studies 11(1) : 25-36.

Irving, J C and Elley, W B (1977) A socio-economic index for the female labour force in New Zealand New Zealand journal of educational studies 12(2) : 154-163.

Kerr. C; Dunlop, J T; Harbison, F H and Myers, C A (1973) Industrialism and industrial man Hardmondsworth, Penguin Books.

Price, R and Bain, G (1983) Union growth in Britain: Retrospect and prospect British journal of industrial relations $21(1): 46-68$. 
Routh, G (1980) Occupation and pay in Great Britain, 1906-1979 (second edition) London, Macmillan.

Smith, D F (1981) Assessing the growth of New Zealand's white-collar workforce Australian and New Zealand journal of sociology 17(2): 77-84.

Smith, D F (1983) Occupational segregation amongst white-collar workers in New Zealand New Zealand economic papers 17 : 37-49.

Smith, D F (1984) An investigation into the growth and unionisation of New Zealand's white-collar workforce A Research Report to the Social Sciences Research Fund Committee, Department of Business Administration, Victoria University of Wellington. 